\title{
aniki
}

Revista Portuguesa da Imagem em Movimento

Portuguese Journal of the Moving Image

\section{Memória e identidade: uma jornada semiótica do self em True Detective}

Jeferson Ferro ${ }^{1}$

Fernando Torres Andacht ${ }^{2}$

\section{Introdução}

To have lived is not enough for them. They have to talk about it.

(Samuel Beckett, in Waiting for Godot)

O homem moderno é, essencialmente, um ser à procura de si mesmo. Trata-se de uma inquietação que até hoje reverbera as palavras do príncipe da Dinamarca: diante de um dilema moral, Hamlet pergunta a si próprio, "Ser ou não ser?" Para Harold Bloom, a literatura de Shakespeare representa o nascimento do homem secularizado, e o solilóquio, esse discurso que se faz de si para si, é o modelo narrativo que define o indivíduo moderno. Segundo o crítico, a grande originalidade shakespeariana estaria em sua "representação da mudança ao mostrar os indivíduos ponderando sobre o próprio discurso e modificando-se mediante essa consideração" (Bloom 2012, 62). A partir disso, nossas identidades se fariam com base em nossas próprias reações tanto ao que fazemos como ao que dizemos, ou seja, a narrativa de uma vida passaria a ser um elemento determinante na construção da identidade de seu autofabulador, alguém que inventa ou constrói um relato possível, e não necessariamente verdadeiro, em torno de sua vida. Essa narratividade autobiográfica parece ser a espinha dorsal do projeto existencial de nosso tempo. Como podemos, então, entender o processo narrativo de momentos de uma vida, que se constrói partindo de um exercício de memória, como fundamento da "jornada do eu"? Nesse artigo, buscaremos compreender esse processo a partir de sua representação em uma cena de True Detective, baseando-nos sobretudo na interpretação de Fernando Torres Andacht e Mariela Michel (2005) sobre o self semiótico, e de Joseph Ransdell (1997) a respeito do signo icônico em Charles Peirce $^{3}$.

\footnotetext{
${ }^{1}$ Escola Superior de Comunicação, UNINTER, CEP 80410-150 Curitiba, Paraná, Brasil.

${ }^{2}$ Facultad de Información \& Comunicación, Universidad de la República, 11200 Montevideo, Uruguay.

${ }^{3}$ Agradecemos aos revisores por suas críticas e observações, que nos foram muito úteis no processo de revisão do artigo, contribuindo de forma significativa para o aprofundamento da discussão e para a reelaboração do texto aqui apresentado.
} 
Independente do fato de ter ou não se manifestado discursivamente pela primeira vez na voz teatral elisabetana de Hamlet, a angústia existencial do homem moderno, encarnada no exercício do autoquestionamento, na busca incessante pela consciência de uma identidade última, se apresenta enredada em processos narrativos cuja matéria-prima é a memória, o que significa dizer que a noção de quem sou depende da narrativa que crio sobre quem fui. Como aponta Anthony Giddens (1992, 41), "Hoje em dia, o eu é para todos um projeto reflexivo - uma interrogação mais ou menos continuada do passado, do presente e do futuro." $\mathrm{Na}$ contemporaneidade, a relação entre as práticas de rememoração e o projeto de identidade se intensifica, na medida em que o desenvolvimento tecnológico nos facilita cada vez mais a captura e a exibição dos signos que produzimos intencionalmente para representar nossa existência - posts, Instagram stories, fotos etc. Se na sua origem a Internet era um espaço privilegiado para o exercício da alteridade, possibilitando aos usuários criarem identidades virtuais radicalmente distintas das que possuíam no mundo off-line, na atualidade essa relação se inverteu. Como aponta Liesbet van Zoonen, a desconexão entre identidade virtual e identidade real se tornou um fator de risco, e a vigilância online se tornou um elemento de grande pressão no sentido de fortalecer "identidades unitárias e estáveis" (2013). Se Facebook e Google são atualmente, graças ao 'Big Data', capazes de dizer com grande precisão quem nós somos a partir de nossos rastros virtuais, por outro lado "abandonar as redes sociais significa excluir-se de espaços vitais do convívio social contemporâneo" (Tufecki 2014, 17).

Desta forma, a extensão virtual de nossas existências transforma-se num interminável livro de rascunhos para a narrativa do self. Uma rede social como o Facebook, por exemplo, com seus vídeos de recordações gerados por algoritmos, nos impõe uma narrativa das memórias que escolhemos expor no universo virtual ao longo dos últimos doze meses, criando uma ordenação destes signos virtuais da identidade que buscam dizer quem somos (ou quem "fomos") para um vasto conjunto de amigos e voyeurs virtuais. Os solilóquios facebookianos são discursos que se produzem para ninguém e para todos ao mesmo tempo. Não deixa de ser irônico que tais narrativas geradoras de nossas identidades virtuais estejam sendo criadas por "máquinas sem consciência".

A produção audiovisual, como não poderia deixar de ser, tem direcionado suas lentes com grande interesse sobre as relações entre memória e identidade no cenário atual. A ficção científica, notadamente, tem sido um gênero privilegiado para a exploração dos conflitos em torno da relação "memória \& identidade" como elemento central da narrativa do eu. Isso não quer dizer, todavia, que os debates em torno da questão estejam exclusivamente vinculados a este gênero. Assim, ainda que neste trabalho nosso objeto de análise, a série True Detective, não seja um exemplo de ficção científica, julgamos relevante mencionar alguns casos atuais que se destacam no conjunto daquele gênero, pois nos oferecem interessantes 
exemplos para desenvolver uma comparação com o processo de identidade, que é o que realmente nos interessa aqui.

Três episódios da série Black Mirror (2011-17) merecem atenção. Em "The entire history of you" (Temp 1, 2011, Jesse Armstrong), os humanos possuem equipamentos de gravação instalados em seus olhos para capturar tudo aquilo que acontece em suas vidas, e assim fazem com que os arquivos de memória, onipresentes, tenham catastróficos impactos sobre suas relações. Diante da possibilidade - que acaba se impondo como uma obrigação obsessiva - de rever todas as suas ações passadas, bem como as de outras pessoas de seu convívio, nos mínimos pormenores, os personagens desta ficção distópica são desprovidos da liberdade de escolha que está na essência do ato narrativo: não há espaço para a edição, sequer para a dúvida. Trata-se do reverso da distopia clássica de 1984, de George Orwell (1948), em que o Departamento da Verdade reescreve as memórias coletivas dos cidadãos, impondolhes uma versão completamente alterada dos acontecimentos. Já em "Be right back" (Temp 2, 2013, Charlie Brooker), uma mãe recémenviuvada "ressuscita" seu falecido marido a partir de seus rastros virtuais, que são transferidos para um robô - uma reprodução fiel de seu corpo. O clone construído a partir da memória do homem armazenada na web, no entanto, não se mostra capaz de tornar-se um signo convincente para a esposa enlutada. Por fim, em "Crocodile" (Temp 4, 2017, Charlie Brooker), um assassinato, até então encoberto por sua criminosa de forma bem-sucedida, é revelado graças a uma "máquina de memória", o equipamento empregado por empresas de seguros para captar todas as lembranças que a memória humana guarda dos fatos vividos por seus proprietários, servindo o propósito de solucionar casos de acidente suspeitos, a que todos os cidadãos devem se submeter por força da lei. Mais uma vez nos deparamos com a distopia ou pesadelo de um mundo inumano da memória total. Ao longo desta série, somos convocados a experimentar o terror provocado pela impossibilidade de se esquecer, ou ainda pela abolição da privacidade da memória, em cenários em que prevalece o tom apocalíptico. Desprovidos da capacidade de edição de nossas memórias, do necessário e seletivo esquecimento, o que aconteceria com a narrativa autofabuladora enquanto prática de recriação constante de nossa identidade?

$\mathrm{Na}$ série Westworld (2016), o domínio sobre a memória constitui a linha que separa humanos de robôs e caracteriza o conflito central da narrativa: os robôs vivem presos em loops de falsas lembranças, criadas por seus desenvolvedores, e são incapazes de saber, e consequentemente de agir a partir disso, o que realmente "viveram", quem são seus inimigos e qual é sua origem. Na segunda temporada da série, eles se lançam numa cruzada pela liberdade movidos pela busca de uma recordação de seu "passado original". Já na mais recente Altered Carbon (2018), série produzida pela Netflix, os seres humanos são reduzidos em sua essência a um disco rígido onde se guardam todas as suas memórias - o que, para os mais abastados, torna-se um arquivo na nuvem, prontamente copiado para 
um novo organismo, sempre que necessário - relegando o corpo ao papel de involução provisório e abrindo as portas para a perspectiva de uma vida eterna (e de uma memória praticamente infinita). Por fim, em Blade Runner 2049 (2017), sequela do filme clássico de 1982, o protagonista, K. (um agente robô), começa a duvidar de sua natureza artificial e se embrenha em uma jornada para descobrir sua verdadeira origem. Para tal fim, ele segue a pista de uma suposta recordação da infância. Em todos estes casos, o fio da memória, seja ele de uma rigidez esmagadora ou apenas uma frágil reminiscência que ilude a consciência presente, estrutura a narrativa e a busca dos personagens pela descoberta de suas identidades.

\section{Memória e identidade}

Longe dos cenários distópicos e dos embates em torno da questão da consciência que opõe a natureza humana à da máquina, nesta análise abordaremos um processo narrativo desencadeado pela recordação, centrado num discurso do sujeito moderno em conflito com sua identidade, numa narrativa situada em uma cidade fictícia dos EUA, na atualidade. A memória será tomada enquanto o fio de amarração do "si mesmo" a partir da narrativa exercida pelo indivíduo, aquilo que une os pedaços dispersos de sua existência, partindo de um exercício de lembrança que, enquanto ato narrativo, tem o papel de organizar e dar sentido ao que não se compreende no presente imediato. Um signo do passado que ressurge para abrir portas de significação e apontar para uma interpretação mais apurada, direcionada ao futuro, tal qual o processo da semiose na concepção peirceana: uma jornada que parte do objeto dinâmico ${ }^{4}$, isto é, o mundo tal qual ele é, antes de ser transformado e limitado a uma ideia (objeto imediato) através de qualquer representação, e passa por uma representação possível em direção ao interpretante final, um signo que vai se elaborando e crescendo no longo prazo, uma espécie de horizonte epistemológico ou ponto final - porém um destino que não tem data de chegada.

Isto significa entender que, mais do que um ponto de partida ou de chegada, a memória é um exercício contínuo de ressignificação, uma cadeia da semiose, o processo que nos define transitoriamente enquanto signos eternamente incompletos que somos, ainda que mesmo assim estejamos o tempo todo em busca de definições. No ensaio em que examina as Confissões de Santo Agostinho em aproximação a Esperando por Godot, de Samuel Beckett, tomando como tema central a questão da memória, Olney afirma que, para Agostinho, "A memória [...] deveria ser o fiador da identidade e da continuidade do ser através do tempo, a única ligação - mas ainda assim uma ligação ininterrupta e perfeitamente competente - entre a experiência do passado e a consciência

\footnotetext{
${ }^{4} \mathrm{Na}$ definição original de Peirce, "the Object as it is regardless of any particular aspect of it, the Object in such relations as unlimited and final study would show it to be." (CP 8.183). Citamos The Collected Papers of C.S. Peirce (1936-1958) de forma convencional: x.xxx remete ao volume: parágrafo; traduções nossas.
} 
presente"5 (1993, 861). Na interpretação de Agostinho, o tempo de Deus é um eterno presente, de forma que, se concebemos três instâncias temporais distintas, elas devem antes ser entendidas como "a lembrança presente das coisas passadas, visão presente das coisas presentes e esperança presente das coisas futuras" (Confissões, livro $11,20)$. Olney destaca a passagem em que Agostinho fala da recitação de um salmo como um exemplo da síntese destes três tempos: "A vida deste meu ato divide-se em memória, por causa do que já recitei, e em expectação, por causa do que hei de recitar. A minha atenção está presente e por ela passa o que era futuro para se tornar pretérito" (28).

Por que, então, narrar-se, rememorar, confessar a Deus algo que ele já sabe, visto que a consciência divina não distingue passadopresente-futuro, mas existe num tempo sintético, todo-abrangente? Se para Agostinho trata-se de uma questão de fundamento da fé religiosa - "Narro estas coisas pelo desejo de Vos amar" (Confissões, livro 11,1$)$-, para Olney o ato de narrar a vida é "uma tentativa eternamente repetida de se encontrar a linguagem apropriada para descrever o eu e sua experiência, uma tentativa que inclui em si mesma todas as tentativas anteriores, ao mesmo tempo que as retoma enquanto experiência nesta última instância"6 (1993, 865). Por isso, o autor considera as Confissões a primeira obra a oferecer uma justificativa para o processo de "escrita da própria vida, de se encontrar as palavras que significam o eu e sua história"7 (858).

Não nos interessa aqui aprofundar a discussão metafísica da concepção de tempo de Agostinho, mas nos parece haver um interessante paralelismo entre a síntese temporal, representada por ele no exercício da recordação, e a natureza triádica do signo peirceano: identidade, memória, síntese de três tempos. Para Peirce, o "si mesmo" é fruto de um processo lógico de significação/interpretação que se desenvolve no tempo. Se para Agostinho o presente é a mediação entre o pretérito e o futuro, para Peirce (conforme modelo apresentado por Wiley; Andacht 2005), a identidade se forma a partir de uma relação triádica que envolve um "eu passado", um "eu presente" (mediador), e um "eu futuro" (sua síntese provisória). Tal processo acontece conforme a estrutura do modelo triádico do signo peirceano, qual seja, a relação entre aquilo que é representado (o objeto), aquilo que o apresenta de algum modo aos sentidos (o representamen), e o efeito de sentido (o interpretante) (CP 2.228), que está no cerne desta teoria da significação como a geração lógica e autônoma de sentido (Ransdell

\footnotetext{
${ }^{5}$ No original: "Memory [...] should be the guarantor of identity and continuity of being across time, the only liaison - but an unbroken and fully capable liaison all the same - between past experience and present consciousness." Tradução nossa. ${ }^{6}$ No original: "...a perpetually renewed attempt to find language adequate to rendering the self and its experience, an attempt that includes within itself all earlier attempts and that draws up behind it all these earlier attempts in this latest quest". Tradução nossa.

${ }^{7}$ No original: "The entire justification, validation, necessity, and indeed exemplary instance of writing one's life, of finding the words that signify the self and its history". Tradução nossa.
} 
1989). Resguardadas suas diferenças, ambos os pensadores compartilham o entendimento do exercício da memória enquanto um ato de produção de significado que opera uma união de três tempos, e desta maneira se manifesta como um processo contínuo constituidor de nossa identidade (Andacht, Michel 2005), que, portanto, não deixa de crescer em complexidade ao longo da vida. Tal concepção da memória será fundamental para nossa interpretação semiótica do self a partir do processo de lembrança no episódio de ficção televisiva escolhido.

Neste trabalho, analisamos a cena de abertura (1'37" a 6'33") do segundo episódio, "Night Finds You", da segunda temporada da série televisiva True Detective (2015), de forma a investigar como um ato reflexivo provocado por um objeto externo desencadeia um inquietante processo de lembrança no protagonista, Frank, envolvendo-o num diálogo de caráter fortemente autorreflexivo e existencial. Se na tragédia mais conhecida de Shakespeare é o fantasma do pai - que traz consigo a opressão de um pedido que o filho não parece ser capaz de aceitar ou realizar, causando-lhe um pesado sentimento de culpa - que lança o jovem Hamlet num profundo solilóquio, levando-o a questionar sua razão de estar neste mundo, o que faz com que Frank em True Detective seja arrastado para a cadeia semiótica da busca da identidade é uma simples mancha no teto de seu quarto. Este elemento externo é um exemplo paradigmático da intrusão de uma força bruta na vida, algo que desloca e aprisiona sua atenção sem que se possa evitá-lo, e que exige dele uma resposta imediata - a qual surge no episódio em forma de um diálogo dominado por uma lembrança de infância. O processo da semiose originada pela aparição da mancha no teto do quarto de Frank, no entanto, não se encerra na própria cena, mas gera a potencialidade da síntese - que produzirá sua significação em um nível mais completo - sempre aberta a uma determinação impossível de conhecer de antemão. Naturalmente, no universo da ficção, a interpretação é uma etapa que cabe ao espectador completar. Diferentemente da vida real humana, em que seus protagonistas não têm a chance de ver como se encerra sua própria jornada, já que morrem no final, na ficção podemos experimentar de modo vicário uma vida imaginada e representada do começo ao fim. Ela é apresentada enquanto um fascinante encadeamento de signos fechado materialmente - embora seja sempre aberto por se tratar de signos estéticos que nos convidam a prolongar e a multiplicar a atenção hermenêutica, a tentar diversas estratégias interpretativas. $\mathrm{E}$, justamente por isso, diante do ponto final da história, podemos chegar, naquele momento, à síntese semiótica da jornada desta vida ficcional, mas verossímil, que se encerrou no relato audiovisual. Nossa análise pretende sublinhar alguns elementos que contribuem para uma interpretação da jornada de Frank naquele momento específico do relato que ele habita. 
Um dos aspectos mais destacados desta série aclamada pela crítica $^{8}$ é sua complexidade imagética, que exerce um papel fundamental na narrativa. Juntamente com a natureza indicial do signo, que estará no centro de nossa análise, a mancha no teto, suas características icônicas serão determinantes para a semiose. A vinheta de abertura é uma prévia desta característica definidora em True Detective: imagens e sombras dos personagens principais deslizam sobre um fundo composto por fotografias da cidade de Vinci, o espaço ficcional onde a narrativa acontece, e seus corpos e rostos se misturam aos prédios, campos e rios da cidade. Este quadro é colorido por pinceladas de vermelho, enquanto o balé das imagens é embalado pela música de Leonard Cohen, "Nevermind". Desta forma, nossa análise estará centrada nos aspectos icônicos do processo semiótico, especificamente na ação dos signos qualitativos, uma vez que o foco de nosso questionamento se direciona a uma sequência específica de imagens desta cena. Todavia, antes de entrarmos propriamente na sua análise, será necessário alinhar alguns princípios teóricos que embasam nosso trabalho.

\section{Self e Semiose em Peirce}

Juntamente com uma breve apresentação dos conceitos da semiótica peirceana, em especial sobre os aspectos que nos interessam para essa análise, recorreremos ao trabalho de Andacht e Michel (2005) para uma abordagem do self ou "si mesmo" enquanto produto de uma relação semiótica. Em linhas gerais, pode dizer-se que o modelo semiótico peirceano pressupõe que vivemos em um universo de signos, o que significa que nossa compreensão do mundo é de natureza fundamentalmente semiótica - aqui entendida de forma ampla, como a ciência que estuda os processos de significação humanos e também naturais sem solução de continuidade. Sua empreitada teórica foi uma tentativa de compreender como os significados são gerados por meio do funcionamento dos signos, o que, por sua vez, resulta num crescimento ininterrupto da complexidade destas relações, na medida em que o tempo avança, já que a criação de sentidos funciona a partir de um mecanismo autônomo e contínuo em expansão constante (Ransdell 1992). Em uma de suas muitas definições de signo, Peirce escreve que um signo é "tudo aquilo que por um lado é determinado por um Objeto e por outro determina uma ideia na mente de alguém, sendo que esta última determinação, a que denomino Interpretante do signo, é consequentemente determinada por intermédio daquele Objeto" (CP 8.343). Esta definição de signo coloca em primeiro plano a natureza sígnica como um processo lógico, ou seja, um elemento da cadeia relacional e triádica da semiose, que é a ação dos signos. Todo pensamento ou sentimento é, portanto, parte de uma corrente

\footnotetext{
8 O site www.metacritic.com apontava, em janeiro de 2016, um score de 87 na avaliação dos críticos, com apenas uma resenha negativa na imprensa de um total de 41. Além disso, foi a série estreante com maior audiência produzida pela $\mathrm{HBO}$, até hoje.
} 
contínua de semiose, que é o processo lógico de produção de signos interpretantes em uma relação triádica: o signo intermedia nossa relação com o objeto, isto é, com o mundo, quer empírico e concreto, ou imaginário, produto da fantasia, o que resulta na produção de um interpretante, que é um signo mais desenvolvido, o qual, por sua natureza sígnica, gera outra corrente sucessiva, na qual o interpretante gerará um novo signo, e assim por diante, indefinidamente. Signos são, consequentemente, definidos por suas relações lógicas com o objeto e o interpretante (Andacht 2013), dentro de um processo de continuidade lógica, ou "sinequismo", que propõe uma conexão falível e incompleta, mas real, entre os signos e a realidade por aqueles revelada. O signo, o objeto que representa e a interpretação que produz formam a cadeia inquebrável da semiose, fora da qual nenhuma significação nem acesso ao mundo externo ou interno - pois os pensamentos e as lembranças são também parte deste processo - é possível.

Outro aspecto fundamental desta teoria é que o processo da semiose, ao menos em parte, está além do controle humano, ainda que esteja em uma relação fundamental com a ação humana, uma vez que "os signos agem como tendências autônomas na produção de sentido" (Andacht 2013, 31). Todavia, não se trata de dizer que qualquer significado é um resultado igualmente possível de uma dada relação triádica, o que implicaria no relativismo absoluto, ou ainda que a significação seja totalmente independente da ação humana, o que seria uma posição teórica próxima do positivismo radical. Como aponta Ransdell:

Criação e mudança de significados é fundamentalmente uma função das disposições e espontaneidades dos signos em si mesmos; e, embora possamos desenvolver nossas habilidades de produção criativa, o resultado de nosso esforço nunca é um produto exclusivo do que nós fazemos: o homem propõe, mas o signo dispõe. (1992: 03; tradução nossa)

Estudar a semiose, consequentemente, é uma tentativa de capturar e descrever tais "disposições e espontaneidades" possibilitadas pelos signos - dentro do escopo das interações humanas -, o que é válido tanto para as relações humanas no mundo real quanto para aquelas que são construídas em mundos ficcionais.

Nossa percepção do mundo é "fenomenológica" no sentido em que percebemos tudo a nossa volta a partir da experiência que os sentidos nos proporcionam, e nos limites que ela mesma gera em nossa interpretação. Todo ato de percepção, por sua vez, tende a se transformar num interpretante, um signo simbólico por natureza, uma vez que é fruto de uma interpretação que acontece em nossa mente, que é outro signo cuja finalidade última é a de ser interpretado de certo modo. Os signos que povoam nossa mente possuem relações distintas com os objetos que os determinaram, e consequentemente geram tipos de interpretantes distintos. Conforme descreve Andacht (2013, 1): “A semiose é a jornada 
ininterrupta a partir do objeto dinâmico - o real como ele é além de qualquer representação - através do meio ou representamen até um signo mais desenvolvido do objeto representado, onde o sentido pode ser apreendido, o interpretante." Aqui, o meio (ou representamen) é equivalente ao uso que fazemos neste trabalho da palavra "signo", enquanto parte da tríade "objeto-signointerpretante". Também digno de nota nesta citação é o aspecto da natureza ininterrupta do processo da semiose, que se nos apresenta como este mar interminável de signos pelo qual navegamos por toda a vida. Explorando um pouco mais essa relação do signo com seu objeto e interpretante, lemos em Peirce:

sempre que pensamos, temos presente e nossa consciência algum sentimento, imagem, concepção ou outra representação, que serve como signo. Mas se segue de nossa própria existência [...] que tudo o que está presente para nós é uma manifestação fenomenológica de nós mesmos. Isso não impede que seja um fenômeno de algo independente de nós, assim como o arco-íris é sempre uma manifestação do sol e da chuva. Quando pensamos, então, nós mesmos, como somos naquele momento, aparecemos como um signo. Pois um signo tem, necessariamente, três referências: primeiro, é um signo para algum pensamento que o interpreta; segundo, é um signo por algum objeto para o qual, naquele pensamento, ele é equivalente; terceiro, é um signo em algum respeito ou qualidade, o que o traz em conexão com o objeto. (CP 5.283; grifos no original)

Compreendemos que, quando Peirce fala da relação do signo "para algum pensamento", ele está considerando o aspecto simbólico desta relação, qual seja, a criação de um interpretante, simbólico por natureza9; quando ele fala do "signo por algum objeto", ele está apontando para o objeto representado pelo signo, referindo-se, portanto, a seu aspecto indicial, qual seja, sua relação factual com algo que existe no mundo; e finalmente, quando ele fala do signo "em algum respeito ou qualidade”, está se referindo a seu aspecto icônico, o qual se baseia em uma qualidade intrínseca do objeto. Desta forma, temos aqui mencionados os três aspectos fundamentais da relação entre um signo e seu objeto dinâmico: icônica, indicial, simbólica. Esta tríade semiótica, portanto, não pode funcionar por exclusão. Bem ao contrário, como aponta Ransdell (1997, 17), tudo depende da maior relevância analítica de apenas uma dimensão semiótica, conforme o interesse do pesquisador:

Assim quando identificamos um signo como sendo icônico, por exemplo, isso significa que a iconicidade daquele signo é de um interesse especial para nós, por alguma razão qualquer implícita na situação e propósito daquela análise, sem qualquer implicação no

\footnotetext{
${ }^{9}$ Cabe mencionar que há outras classes de interpretante, quais sejam, o emocional, o energético e o lógico, conforme a classe de efeito produzido na semiose. Desse modo, queremos advertir ao leitor que o interpretante não é apenas simbólico, mesmo se neste artigo essa classe é a única que será a discutida.
} 
sentido de que ele seja, por consequência, não-simbólico ou nãoindicial.

Os três aspectos de apresentação do signo serão também faces do "self semiótico", pois ele será um signo assim como todos os outros. Conforme ressaltam Andacht e Michel (2005, 63), "Nem parte do cérebro, nem uma abstração sociocultural, o self se dá ao conhecimento a partir da sua externalidade; sua mente encarnada". O pensamento, para Peirce, só pode ser concebido como um signo, e, portanto, como elemento de uma semiose. O self é produto de um processo reflexivo, e da mesma forma constitui um signo externo, pois:

o autoconhecimento envolve crucialmente a interpretação de si mesmo enquanto um outro. Assim, a experiência de um mundo interior deriva da troca ativa e interminável com o mundo externo. A construção do pensamento enquanto um diálogo interno do self ao longo do tempo é o resultado natural da ação semiótica. Peirce descreve este mecanismo como uma conversa na qual o self do presente - o papel do "Eu" - se dirige ao self do futuro como se fosse um "Você", de forma semelhante à que teria caso se dirigisse aos outros. (Andacht \& Michel 2005, 63)

$\mathrm{Na}$ cena em que nos propomos a analisar, observamos a própria consciência externalizada do personagem, como ele busca entender a si próprio em um diálogo com sua esposa, durante o qual lhe surge uma memória de infância. Esta memória se apresenta como uma metáfora de seu estado atual, um signo interpretativo do seu self, ao mesmo tempo em que se projeta para seu "Eu" futuro, delineando outras possibilidades de interpretação deste signo. Esse processo de discussão permite observar de modo privilegiado a semiose em funcionamento, a geração de novos sentidos que nos aproximam da verdade: "É por meio da autocrítica de nossas interpretações, que são frequentemente enquadradas em uma narrativa, que os significados crescem" (Andacht \& Michel 2005, 67).

Como optamos por destacar o aspecto icônico do objeto que desencadeia este processo de autorreflexão, a mancha dupla no teto $^{10}$, cabe-nos compreender o que define um ícone na semiótica peirceana. Para isso, devemos antes apresentar outra noção triádica, aquela das três categorias fenomenológicas com que Peirce analisa toda experiência, possível, concreta e habitual: Primeiridade, Secundidade e Terceiridade. A Primeiridade se refere ao ícone, uma vez que ele tem como aspecto central a manifestação de uma possibilidade, de uma qualidade absoluta sem considerar mais nada. De acordo com a descrição de Peirce: "Primeiridade é a forma de ser que consiste na existência de seu sujeito tal como ele é,

10 Não obstante, como escrevemos acima, não se trata de um ícone puro, porque essa mancha é um índice ou signo indicial de umidade nesse ponto da casa. Para nossa análise escolhemos nos focar na iconicidade desse elemento do mundo. 
independentemente de qualquer outra coisa. O que só pode ser uma possibilidade." (CP 1.25) A categoria da Primeiridade, portanto, se refere ao signo em seu aspecto único, um elemento isolado, algo ainda não materializado em modo algum. A realização concreta desta "possibilidade", de uma forma ou outra, é o que irá mover a semiose às outras duas instâncias. A Secundidade é a categoria da existência física, aquela que se refere à ligação existencial entre o signo e o objeto. Portanto ela pressupõe uma junção física, dual, que requer necessariamente duas coisas, por exemplo, os sintomas palpáveis ou visíveis de uma doença. A Terceiridade é a categoria que nos leva à dimensão interpretativa do signo mais complexo que é produzido na semiose. Enquanto o ícone é apenas uma possibilidade imaginável aos olhos da mente, o signo icônico, ou hipoícone (CP 2.276), é aquele que materializa sua qualidade distintiva. Conforme esclarece Santaella: "É por isso que, se o signo aparece como simples qualidade, na sua relação com seu objeto, ele só pode ser um ícone. Isto porque qualidades não representam nada. Elas simplesmente se apresentam." (2007, 63; ênfase nossa). E a autora ainda acrescenta: "Daí que o ícone seja sempre um quase-signo: algo que se dá à contemplação" $(2007,64)$.

A análise do funcionamento do signo em si mesmo nos levará a uma outra tríade, equivalente à anterior: qualisigno, sinsigno e legisigno, que resultam da consideração analítica do signo ou representamen em si mesmo. Trata-se de atentar para o que escolhemos como aspecto determinante no signo, seja sua qualidade, sua existência, ou seu aspecto normativo. Aqui novamente é importante lembrar que quando um signo específico é considerado, para propósitos analíticos, como um "qualisigno", por exemplo, isso não implica que não se possa enquadrá-lo analiticamente nas outras categorias. Conforme esclarece Ransdell (1997, 35):

Assim, o mesmo objeto que, a partir de uma perspectiva categorial, é uma qualidade, e, de outra perspectiva, um indivíduo existente, também pode ser pensado, de uma terceira perspectiva categórica, enquanto um poder incorporado (...) não há, em geral, qualquer implicação necessária ligando uma identidade de qualisigno à identidade de sinsigno de algo, nem de qualquer uma delas à sua identidade como legisigno.

Desta forma, podemos entender que este conjunto de relações que a semiótica peirceana procura descrever a partir de suas tricotomias se apresenta enquanto produto do ato interpretativo, sob diferentes vieses de análise do signo. Falar do aspecto icônico de um signo significa direcionar o olhar analítico especificamente para tal aspecto da relação de significação, o que se justifica tão somente por um interesse do pesquisador. Delimitados esses pressupostos teóricos fundamentais, prosseguiremos agora à análise da cena que escolhemos, com o intuito de descobrir o que seus signos podem nos revelar sobre as verdades de sua cadeia semiótica. 


\section{Navegando na corrente semiótica ao encontro da noite imaginada}

Frank é um homem perturbado - nós o conhecemos no episódio 1. $\mathrm{O}$ gângster da cidade - sujeito alto e elegante, mas não tão confortável em reuniões de negócio -, ele está tentando fechar um grande acordo comercial na área imobiliária, um negócio que envolve os homens mais poderosos de sua cidade - um conjunto que inclui o prefeito, para quem ele sempre foi uma espécie de capataz, e ainda investidores estrangeiros. Mas as coisas não estão se saindo muito bem para este homem que sonha em se tornar um respeitável businessman. Ele liquidou seus ativos para levantar dinheiro para o negócio, confiante de que faria a grande virada de sua vida: estava deixando o cassino e a boate para trás e entrando definitivamente no mundo dos homens de negócios respeitáveis. Mas eis que Caspere, seu sócio no acordo, figura pública central na cidade de Vinci e uma espécie de ponte entre o submundo que Frank habita e este universo superior, repentinamente desaparece, e com ele se vai todo o dinheiro levantado pela sociedade, o que ameaça sua sobrevivência imediata. Após ser anfitrião de um tenso coquetel para potenciais investidores no negócio, que são pegos de surpresa pela situação e não escondem o incômodo com a ausência de Caspere, Frank vai pra casa encarar mais uma noite em claro, sem saber o que esperar do dia seguinte.

O episódio Night finds you abre com uma sequência de cenas externas da casa de Frank, chamada de Casa Semyon (sobrenome de Frank), e em seguida a câmera corta para o ponto de vista do teto de seu quarto de dormir, olhando para baixo, focada verticalmente em Frank, que está deitado ao lado da esposa. Estamos nas primeiras horas do amanhecer, sob a luz natural, instantes antes do raiar do dia seguinte ao coquetel, Frank parece que não pregou os olhos durante a noite toda e agora seu olhar se fixa inquisitivamente no teto, quando diz a primeira frase do episódio: "Como é que aquela mancha de umidade foi parar lá? (A câmera corta para duas manchas acinzentadas no teto, diretamente sobre ele)”.

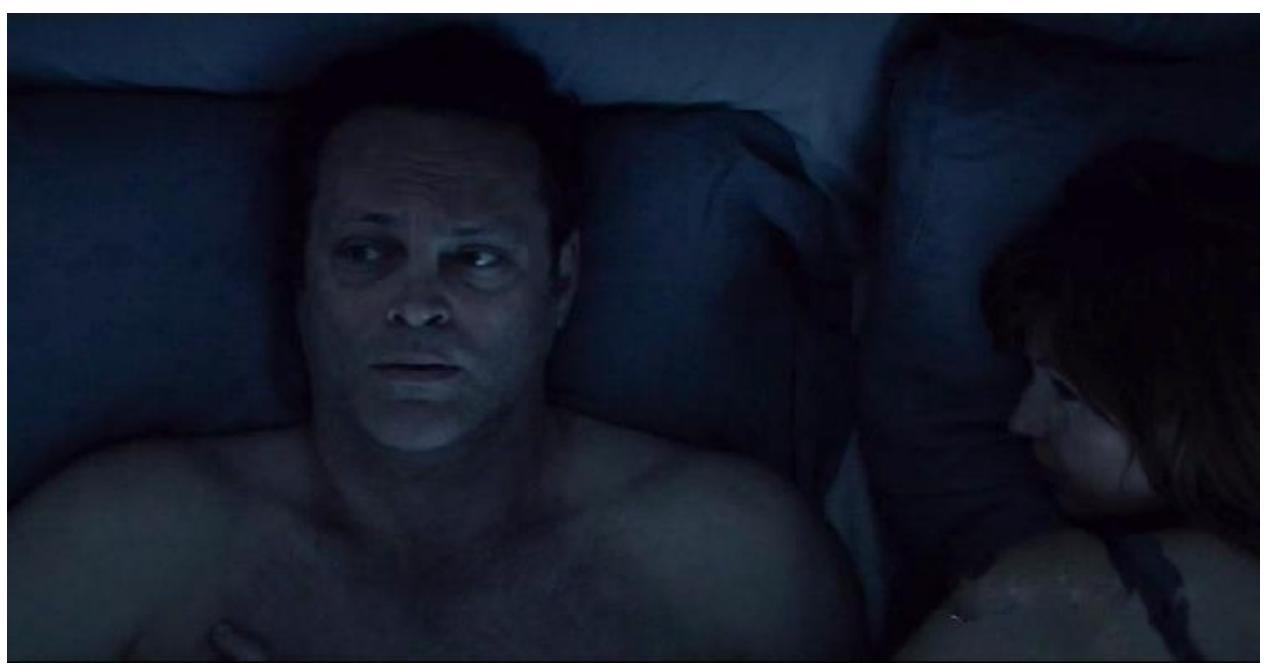




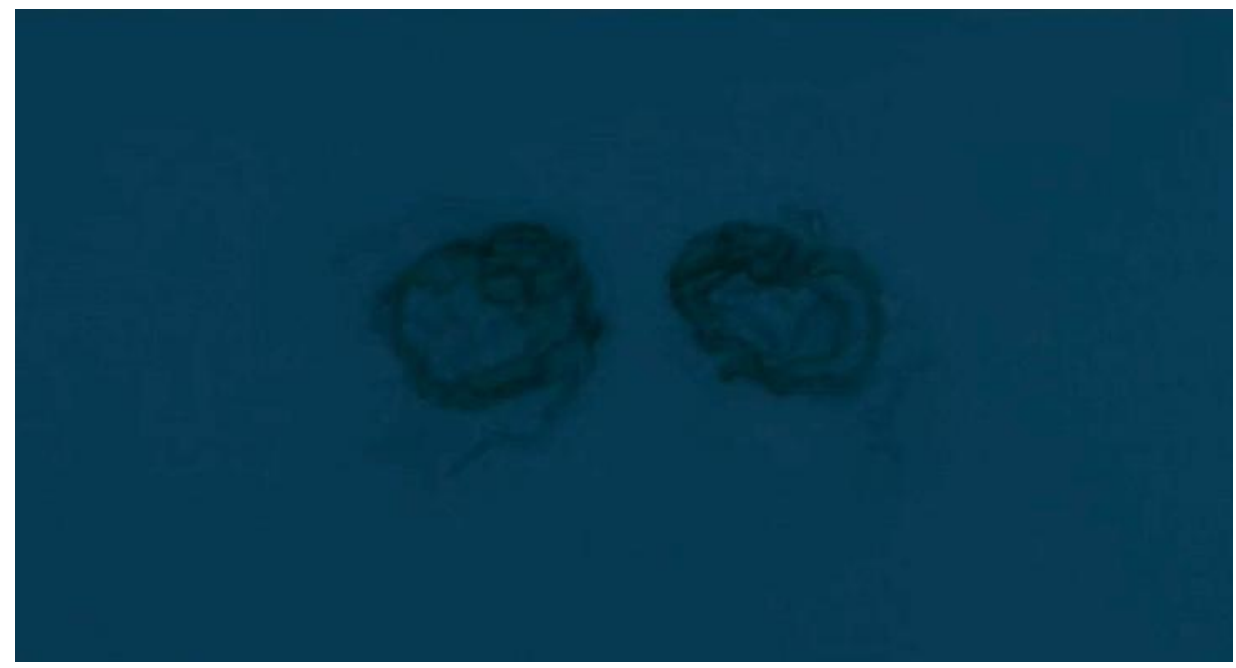

Figuras 1-2: Fotogramas de True Detective, "Night finds you" (2.01). (c) Home Box Office (HBO).

Este momento inicial do episódio nos oferece uma oportunidade de contato com um elemento físico, uma coisa perceptível que fornece o material e a energia necessária para deslanchar o processo de semiose: a dupla mancha de umidade no teto, a qual vai se transformar num objeto semiótico. Conforme Peirce esclarece:

O que o signo virtualmente tem de fazer a fim de indicar seu objeto - e torná-lo seu - tudo o que ele tem de fazer é apenas capturar o olhar do intérprete e forçosamente direcioná-lo para o objeto desejado: é o que uma batida na porta faz (...) É uma compulsão puramente psicológica, nada mais. (CP 5.554)

E, podemos dizer, é exatamente o que a mancha faz: ela captura os olhos de Frank. Esse impacto inicial da mancha a caracteriza como nosso objeto semiótico central nesta cena: ela é "a pura força da categoria da Secundidade, o bruto golpe externo que violentamente agarra nossa atenção, se sobrepondo à qualquer aspecto de apresentação do signo”. (Andacht 2004, 12). A mancha provoca no início uma reação puramente física, e Frank, claramente incomodado por sua presença, reage fazendo a si mesmo um questionamento: "Choveu duas vezes nesse ano?"

A clara natureza indicial deste signo nos leva, naturalmente, a abordá-lo como um "sinsigno" num primeiro momento, que Peirce assim descreve: "uma coisa que realmente existe e que é um signo. Ela só pode sê-lo por suas qualidades; de forma que envolve um 'qualisigno', ou antes, vários qualisignos.” (CP 2.245) A percepção da mancha faz com que Frank mergulhe em uma reflexão existencial como tentativa de compreender seu impacto. Sua esposa, Jordan, agora desperta, será seu par no diálogo. Ela diz a ele:

Jordan: "Pare de pensar."

Frank: "Eu não gosto de estar por um fio."

Jordan: "Ninguém fica rico só com o próprio dinheiro." 
Frank: "Eu nunca soube o que fazer com isso. Dinheiro." (Câmera corta para a área externa da casa; Tadução nossa.)

O casal continua a conversar, enquanto vemos algumas imagens da casa - uma propriedade luxuosa, no topo de uma montanha, decorada de forma impecável, com uma bela vista sobre a cidade - entremeadas por closes dos seus rostos:

Frank: "Hoje percebo isso sobre mim."

Jordan: "Você sempre disse que quer ter muitas propriedades."

Frank: "Sim, mas você tem que ter filhos pra quem deixar. Nunca é realmente seu. Você não leva com você."

Jordan: "Você não leva nada com você."

Frank: "Só você mesmo, o que quer que tenha sido."

Jordan: "Eu batalhei a vida inteira. Como você. E não ser pobre é melhor do que o oposto disso."

(Tadução nossa.)

O surgimento da mancha de umidade, sua natureza física concreta, nos direciona à ideia de semelhanças em potencial, da qual extraímos duas possíveis interpretações: 1 . a imagem dos testículos de um homem, ou ainda dos ovários da mulher, o que representa os órgãos da fertilidade; 2 . um par de olhos. A discussão sobre dinheiro, assunto que está no centro das preocupações do casal, traz à tona uma outra tensão, além da situação periclitante do negócio que ele está tentando fechar, que tem definido a relação entre Frank e Jordan: suas tentativas frustradas de engravidar, uma situação que se desenvolverá ao longo dos episódios seguintes, mas que surge aqui de forma embrionária na narrativa. Em um capítulo futuro da série, descobriremos que Frank é fértil, mas Jordan não, o que basicamente anula o sentido de sua vida a partir da reflexão desencadeada pela mancha nesta cena - uma interpretação fortalecida pela sucessão de imagens da casa vazia sob a meia-luz da alvorada. Sua vida, até então movida pelo desejo de acumular dinheiro, é esvaziada pela perspectiva de não deixar herdeiros. Tal interpretação, todavia, a essa altura da história é uma possibilidade narrativa ainda um tanto distante, uma vez que não temos a informação a respeito da infertilidade de Jordan - embora isso tenha sido sugerido. De qualquer forma, esse desenvolvimento futuro mantém o signo vivo dentro da narrativa, se desenvolvendo, conforme o princípio peirceano de que "os símbolos crescem" (CP 2.302), acrescentandolhe novas possibilidades interpretativas na medida em que a história prossegue. Se contemplamos a imagem da mancha como sendo um ícone dos órgãos reprodutores do homem e da mulher, isso quer dizer que estamos pensando nela enquanto um legisigno icônico, o que Ransdell (1997:41) descreve desta forma:

a concepção do legisigno icônico está sendo implicitamente requisitada toda vez que se identifica em um processo de semiose uma tendência inerente a manter uma certa identidade formal ou qualitativa ao longo de uma série de transições semióticas do signo ao signo interpretante. Legisignos icônicos estarão normalmente em 
comunhão com legisignos indiciais e simbólicos como fatores de controle no processo semiótico, todavia, com o legisigno indicial funcionando para manter a identidade da referência ou origem do pensamento, e o legisigno simbólico fornecendo os contornos do aspecto télico, propositivo ou direcional do processo.

Assim, entendemos que a forma da imagem da mancha corresponde à "identidade formal ou qualitativa" que permanece estável e será igualmente aplicável para a outra interpretação muito diferente do signo icônico - a dos "olhos". A interpretação da mancha por uma semelhança com os órgãos reprodutores só é possível a partir da conversa que Jordan e Frank travam na cama, que são os "legisignos simbólicos fornecendo os contornos" da semiose, conforme explica Ransdell (1997).

Mas o impacto da mancha não se encerra ali. A reflexão de Frank de repente se transforma em digressão, e ele resgata uma memória traumática da infância. Quando tinha seis anos de idade e vivia com o pai alcoólatra, costumava ficar trancado no porão, ao longo da noite, quando o pai saía de casa para se embebedar. Uma certa vez, seu pai não retornou pra casa na manhã seguinte, e ele acabou ficando preso lá por cinco dias, sozinho, sem comida e no escuro. No momento mais dramático deste confinamento, o menino Frank esmagou com as próprias mãos um rato que lhe mordiscava os dedos. Agora a presença da mancha de umidade no teto de sua casa "dos sonhos" o transporta para aquele momento de máxima vulnerabilidade, resgatando uma memória nada agradável, que ele se sente impelido a revisitar:

Jordan: “Às vezes eu me pergunto quantas coisas deste tipo você tem guardadas. E que eu não sei a respeito."

Frank: "Desde então, eu me pergunto: e se ele nunca voltasse pra casa? E se eu ainda estiver naquele porão escuro? E se eu morri lá? É disso que ela me lembra?"

Jordan: "Ela?"

Frank: "A mancha de umidade. Algo está tentando me dizer que é tudo papel-machê. Algo está me dizendo pra acordar. Como... como se eu não fosse real. Como se eu apenas estivesse sonhando.”

(Tadução nossa.)

Estamos olhando para Frank e Jordan exatamente do ponto de vista da mancha, com a câmera focalizando-os verticalmente de cima pra baixo. Em um nível metaficcional, podemos entender a fala de Frank como dirigida a nós mesmos, os espectadores, como se aquela mancha representasse nosso par de olhos se intrometendo na cena. Tal interpretação estaria em sintonia com a dúvida reflexiva expressa por Frank: ele não é real, mas só uma peça de ficção. A mancha seria, novamente, conforme nossa análise, um legisigno icônico, representando o par de olhos de um observador externo, uma interpretação para a qual a fala de Frank aponta explicitamente. Recorremos aqui mais uma vez a Ransdell (1997, 39): 
Um uso da concepção de legisigno icônico seria na descrição de um processo semiótico no qual uma certa forma ou qualidade se mantém ao longo da cadeia do processo, de forma que cada interpretante icônico sucessivo parte de, ou ainda incorpora, algo externo ao ícone propriamente inserido em cada membro da cadeia (em virtude do que a cadeia é iconicamente unitária), ou ainda simplesmente duplica o signo anterior em seu aspecto icônico.

Esta "duplicação" de que fala Ransdell ganhará um aspecto literal no fechamento da cena que estamos analisando: a câmera se distancia de Frank e Jordan, ainda deitados na cama e olhando pra cima, com a seguinte descrição no roteiro: "Corta para a mancha no teto. Então corta para: Int Morgue - Close na cabeça de Ben Caspere e nos buracos de seus olhos" (sequência exibida na figura abaixo). A mancha que olha para o casal, por obra da montagem, instantaneamente se transforma no par de olhos de Caspere. Dentro de alguns segundos, ficaremos sabendo que ele morreu em uma sessão de tortura: alguém pingou ácido em seus olhos enquanto ele estava amarrado em posição dorsal.

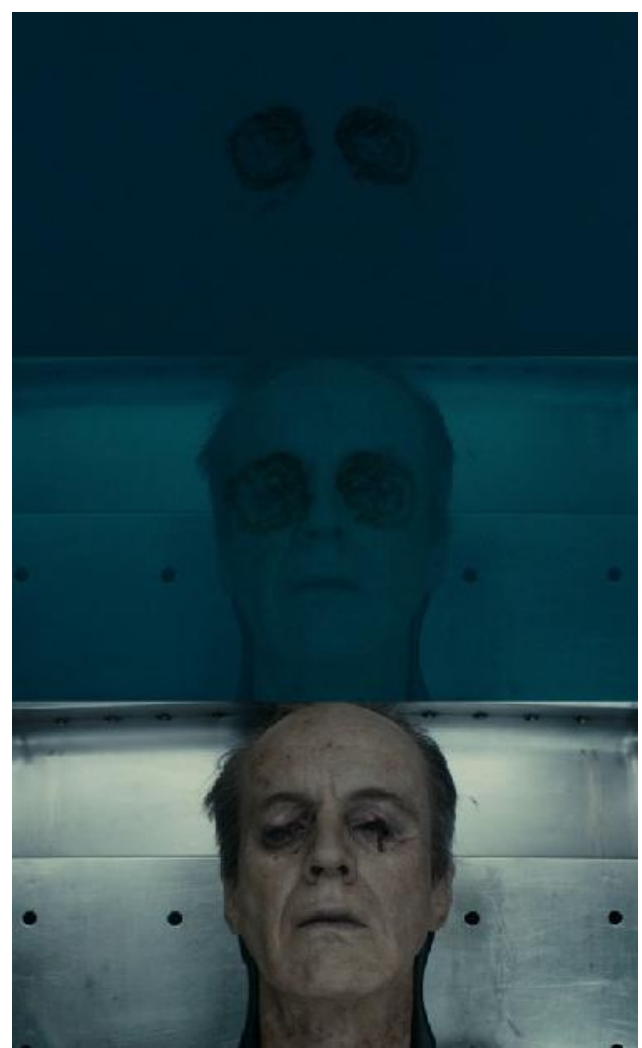

Figura 3: Fotograma de True Detective, "Night finds you" (2.01). ㄷ Home Box Office (HBO).

A jornada semiótica de Frank se inicia pelo confronto com a mancha que o olha de cima, como um futuro inescapável que o espreita assustadoramente. Trata-se do reconhecimento da realidade externa, que está além do seu controle, como comentam Andacht e Michel (2005, 59): 
Quando Peirce escreve que "o sentido de externalidade na percepção consiste em um sentimento de impotência diante da força dominadora da percepção" (CP 1.334), ele nos oferece uma apreensão semiótica de uma experiência de crescimento básica no processo do desenvolvimento humano, qual seja, a aceitação dos rígidos limites do mundo real, que é o que gradualmente encerra o sentimento de onipotência de uma criança.

Pois é este sentimento de impotência diante da mancha, percebido por Frank, que o coloca diante "dos rígidos limites do real" e o aproxima de uma aceitação de sua realidade indigesta, insuportável: os negócios não vão bem e caminham para um beco sem saída; além disso, ele não terá filhos, o que faz com que sua luta para enriquecer, o objetivo de toda uma vida, pareça banal, inútil e inócua. A mancha coloca sua vida em perspectiva, traz à tona uma memória traumática e desencadeia um processo autorreflexivo que põe sua identidade em cheque. E assim, esse elemento aparentemente trivial do relato nos permite desenvolver uma interpretação a partir de seus aspectos enquanto signo icônico, remetendo-nos à questão da infertilidade. Não só do ponto de vista biológico, mas como um símbolo maior da vida deste personagem: uma vida sem a perspectiva da continuidade, do legado; uma vida que se encerra em si mesma - o que leva Frank a questionar se ele está, de fato, vivo.

Essa interpretação a que chegamos para a semiose da identidade de Frank é, em suma, a síntese que nós, espectadores, podemos realizar a partir da abordagem semiótica de sua trajetória ficcional. Nosso olhar para a cena é certamente mais abrangente do que o do personagem, pois a narrativa nos permite ver além do que ele vê - inclusive, a transformação da mancha nos olhos perfurados de Caspere. No entanto, fomos convidados persuasivamente a vivenciar seu conflito identitário por meio de seus próprios olhos, de sua consciência que opera o resgate da memória de infância que coloca em xeque sua identidade, sua existência futura. Nesse sentido, não podemos dissociar nossa própria consciência interpretativa daquela que nos é apresentada pela narrativa como sendo a consciência do personagem. Conforme aponta Goffman, a essência da ficção está calcada na sua capacidade de proporcionar o envolvimento (engrossment) do espectador de tal forma que provoque sua efetiva imersão no universo narrativo: “...o envolvimento de um leitor com um episódio de um romance é, naquilo que realmente importa, o mesmo que seu envolvimento em uma sequência de experiências 'reais'11" (1986, 347). Assim, por força do efeito mimético, nossa jornada de percepção como espectadores só pode existir enquanto uma determinação da jornada do protagonista.

\footnotetext{
${ }^{11}$ No original: "a reader's involvement in an episode in a novel is in the relevant sense the same as his involvement in a strip of 'actual' experience."
} 


\section{Conclusão}

Em comentário ao trabalho de Colapietro sobre o self semiótico, Andacht e Michel concluem que "tornar-se um self (...) implica, na verdade, um envolvimento constante em uma atividade semiótica autocontrolada que é inseparável da busca falível de um ideal de evolução" (2005, 73). O homem moderno, de Hamlet a Frank Semyon, é um ser que verbaliza seus pensamentos e narra suas memórias num processo contínuo de autodefinição crescente. $\mathrm{Na}$ cena de True Detective que nos propusemos a analisar, encontramos um exemplo emblemático deste processo narrativo do eu, um rico conjunto de signos organizados numa narrativa de ficção audiovisual, e carregados de potencial interpretativo futuro. Partimos da concepção de self enquanto uma unidade transitória que se desenvolve no processo autorreflexivo decorrente do confronto com a realidade bruta. Esta "revelação progressiva da realidade 'bruta' através dos signos, que é um esforço intencional, falível, determinado - no sentido de ser limitado - pelo objeto semiótico" $(2005,58)$ é o motor do processo identitário de nosso personagem, que se encontra em um momento decisivo da vida.

A relevância do nível imagético ao longo da narrativa nos direcionou para o aspecto icônico da comunicação. Para Peirce (CP 2.92), os ícones são signos da categoria da Primeiridade que guardam um potencial de interpretação calcado em suas qualidades intrínsecas. É a partir desse princípio que buscamos traçar interpretações possíveis à imagem da mancha no teto, e ao efeito de sua aparição para o desenrolar da trama. Como uma obra de ficção, Night Finds You nos permite enxergar uma cadeia semiótica fechada, da qual a síntese ou efeito de sentido - ou seja, a produção do interpretante - depende de nosso olhar interpretativo enquanto público conhecedor / informado desta série.

Escolhemos focar no aspecto icônico do processo partindo do princípio de que a iconicidade é "o reconhecimento da única forma pela qual podemos nos familiarizar com as formas da experiência, com a dimensão qualitativa do que percebemos, e com o que sonhamos ou imaginamos" (Andacht 2004, 11). A aparição da mancha de umidade no teto é uma experiência desencadeadora de uma cadeia de interpretações que nos revelaram a sujeira ou a escuridão sórdida que se esconde por baixo da superfície imaculada do lar de Frank e Jordan, o que serve como metáfora perfeitamente apropriada para sua existência, ao mesmo tempo em que aponta para o "Eu" futuro da sua identidade em transformação. É esta rica relação entre texto e imagem o que constrói profundas camadas de sentido para essa narrativa, caracterizando True Detective como uma obra de ficção serial de qualidade destacada. 


\section{BIBLIOGRAFIA}

Agostinho, de Hippo, Santo. 1999. Confissões. São Paulo: Editora Nova Cultural.

Andacht, Fernando Torres. 2013. “¿Qué puede aportar la semiótica triádica al estudio de la comunicación mediática?” Revista Galáxia, Vol. 12, No. 25, 24-37.

. 2004. "Reflections on Iconic Power. From Technocynicism to Synechism”, Visio International Journal of Visual Semiotics. vol. 9, 1-2, 133- 150.

; \& Michel, Mariela. 2005. "A semiotic reflection on selfinterpretation and identity". Theory and Psychology, Vol. 15 (1): 51-75.

Bloom, Harold. 2012. Abaixo as verdades sagradas - poesia e crença desde a Bíblia até nossos dias. São Paulo: Companhia das Letras.

Giddens, Anthony. 2002. Modernidade e identidade. Rio de Janeiro: Jorge Zahar Editor.

Goffman, Erving. 1986 [1974]. Frame analysis. An essay on the organization of experience. Boston: Northestern University Press.

Olney, James. 1993. "Memory and narrative - the weave of lifewriting". New Literary History, 24: 857-880.

Peirce, Charles Sanders. 1931. The Collected Papers of C. S. Peirce. Charles Hartshorne, Paul Weiss, and Arthur Burks (eds.). Cambridge: Harvard University Press.

Ransdell, Joseph Morton. 1997. "On Peirce's concept of Iconic Sign”. Acedido em 30 de Janeiro de 2019. http://www.iupui.edu/ arisbe/menu/library/aboutcsp/rans dell/ICONIC.HTM

. 1992. "Teleology and the Autonomy of the Semiosis Process". Acedido em 30 de Janeiro de 2019. http://www.cspeirce.com/menu/library/aboutcsp/ransdell/ autonomy.htm

Santaella, Lucia. 2007. O que é semiótica. São Paulo: Brasiliense. . 2002. Semiótica aplicada. São Paulo: Cengage Learning.

Tufekci, Zeynep. 2014. "The Social Internet: Frustrating, Enriching, but Not Lonely”. Public Culture, 26 (1 [72]): 13-23. doi: https://doi.org/10.1215/08992363-2346322

van Zoonen, Liesbet. 2013. "From Identity to Identification: Fixating the Fragmented Self." Media, Culture \& Society 35, no. 1 (Janeiro): 44-51. doi:10.1177/0163443712464557. 


\section{FILMOGRAFIA}

Altered Carbon. Mythology Entertainment, Skydance Television, EUA, 2018.

Black Mirror. Zeppotron, Channel 4 Television Corporation, Gran Babieka, Reino Unido, 2011-2017.

Blade Runner 2049. Realizado por Denis Villeneuve, Alcon Entertainment, Columbia Pictures Corporation, Sony, EUA, Reino Unido, Hungria, Canadá, 2017, 164 min.

'Night Finds You', True Detective. Realizado por Justin Lin, Anonymous Content, Passenger, EUA, 2015, 59 min.

Westworld. Bad Robot, Jerry Weintraub Productions, Kilter Films, EUA, 2016-2018. 